\title{
Yuka Kadoi. «Textiles in the Great Mongol Shahnama: a new approach to Ilkhanid dress »
}

\section{Frantz Chaigne}

\section{Q OpenEdition}

1 Journals

\section{Édition électronique}

URL : http://journals.openedition.org/abstractairanica/42767

DOI : 10.4000/abstractairanica.42767

ISBN : 1961-960X

ISSN : 1961-960X

Éditeur :

CNRS (UMR 7528 Mondes iraniens et indiens), Éditions de l'IFRI

\section{Référence électronique}

Frantz Chaigne, «Yuka Kadoi. «Textiles in the Great Mongol Shahnama: a new approach to Ilkhanid dress » », Abstracta Iranica [En ligne], Volume 37-38-39 | 2018, document 23, mis en ligne le 10 mars 2018, consulté le 02 octobre 2020. URL : http://journals.openedition.org/abstractairanica/42767 ; DOI : https://doi.org/10.4000/abstractairanica.42767

Ce document a été généré automatiquement le 2 octobre 2020.

Tous droits réservés 


\title{
Yuka Kadoi. « Textiles in the Great Mongol Shahnama: a new approach to Ilkhanid dress »
}

\author{
Frantz Chaigne
}

\section{RÉFÉRENCE}

Yuka Kadoi. «Textiles in the Great Mongol Shahnama: a new approach to Ilkhanid dress ", in Kate Dimitrova, Margaret Goehring (eds.), Dressing the Part: Textiles as Propaganda in the Middle Ages, Turnhout: Brepols, 2014, p. 153-65.

1 Kadoi propose ici de montrer en quoi le Grand Shahnama mongol, copié vers 1335 vraisemblablement à Tabriz, constitue une source fiable pour notre compréhension des textiles ilkhanides, dont seul un nombre relativement restreint nous est parvenu. À cette fin, l'auteur se livre à l'examen détaillé de scènes significatives montrant des brocards utilisés dans un contexte funéraire, des robes de cour - mongoles ou islamiques - et des éléments de décor emblématiques du pouvoir, comme les «cloud collars » et les "mandarin squares». L'auteur valide son hypothèse de la fiabilité des illustrations du célèbre manuscrit, en les confrontant à des textiles du Proche-Orient, d'Asie centrale et de Chine contemporains du manuscrit, mais aussi à diverses images issues de ces régions. Les corrélations s'avèrent significatives : elles montrent le souci de réalisme des peintres, offrent des exemples contextualisés de l'utilisation de ces textiles à la cour ilkhanide et soulignent l'intensité des échanges de ces marchandises à travers toute l'Asie. Enfin, Kadoi rappelle que la représentation des héros du Shahnama dans des vêtements effectivement mongols illustre une tentative d'appropriation de la culture persane par la nouvelle dynastie et confirme par là son aspiration à une forme de légitimation. 


\section{AUTEURS}

\section{FRANTZ CHAIGNE}

Chercheur associé, CNRS, Orient \& Méditerranée-«Islam médiéval» 